\section{Construcción de legitimidad en una profesión de asistencia*}

\author{
Constructing \\ the legitimacy of \\ a bealth-care \\ profession
}

Marta V. Schapira**

*El presente trabajo es parte de la investigación 'La práctica odontológica, su lugar en las prácticas del campo de la salud. Construcción histórica y sistemas de representaciones', desarrollada en el Consejo de Investigaciones de

la Universidad Nacional de Rosario

**Antropologa Investigadora del Consejo de Investigaciones de la Universidad Nacional de Rosario (CIUNR) y del Centro de Estudios Sanitarios y Sociales.

Juan M. de Rosas 972/7 B 2000 Rosário Argentina
SCHAPIRA, V. Marta: 'Construcción de legitimidad en una profesión de asistencia'. História, Ciências, Saúde-Manguinhos, IV(3): 461-474 nov. 1997- fev. 1998.

Este artigo mostra como a demarcação deste campo de conhecimento, a odontologia, se articulou com a legislação que a constituiu como profissão entre as práticas de saúde na Argentina, do final do século XIX até a década de 1930. Analisa-se a relação que as associações profissionais mantiveram com as instâncias de formação e legitimação social e jurídica da prática profissional. Numa abordagem que privilegia a construção social, o artigo recupera aspectos sociológicos, antropológicos e históricos do processo de profissionalização e procura identificar atores e modelos de conhecimento relacionados com ele. Focaliza sobretudo a dinâmica da definição de uma área específica que precisou superar obstáculos para adquirir o monopólio de uma prática, alijando profissionais de outras áreas e mantendo uma relação ambivalente com a medicina e o Estado.

PALAVRAS-CHAVE: história da odontologia, história da medicina, Argentina.

SCHAPIRA, V. Marta: 'Constructing the legitimacy of a health-care profession'. História, Ciências, Saúde-Manguinhos, IV(3): 461-474 nov. 1997- fev. 1998.

Focusing on the period from the close of the 19 th century to the 1930 s, the article reveals the interplay between the establishment of a particular field of knowledge - in this case, dentistry - and regulatory legislation in Argentina. The analysis explores professional associations and their relations with degreegranting institutions, the regulation of dental practice, and the social and legal legitimization of the field. Emphasizing issues of social construction, the article examines sociological, antbropological, and historical aspects of the process of professionalization and endeavors to identify the actors and models of knowledge involved. Above all, the article looks at the dynamics entailed in defining an area that had to overcome obstacles to gain monopoly of a practice. In so doing, other bealth-care practitioners were shut out while relations between the medical field and the State were governed by ambivalence.

KEYWORDS: history of dentistry, history of medicine, Argentina. 


\section{Notas metodológicas}

$\mathrm{D}$ esde la perspectiva de la "construcción social", y en una línea que incorpora los desarrollos específicos de Freidson (1994) y Larson (1977) para el estudio de las profesiones, se intenta avanzar por sobre la estrategia de investigación fenomenológica apuntando al análisis de los procesos complejos y conflictivos por los cuales las profesiones emergen, se desarrollan, se consolidan y transforman, en este caso la odontología.

La delimitación de un campo de intervención exclusiva y las modalidades que esta práctica ha adoptado en el campo de la salud, ha encontrado definiciones y redefiniciones en un proceso histórico donde se articulan las formas de asociación institucionalizadas, las instancias formativas reconocidas por el estado, la reglamentación de la práctica y el ordenamiento jurídico en relación con la legitimidad social que se va alcanzando.

Rescato la importancia de las categorías de conflicto y poder que caracterizan los trabajos de la sociología de las profesiones de la década del 1970, particularmente aquellos que enfatizan el carácter ideológico de las demandas profesionales, del monopolio de los privilegios, del ejercicio de la autoridad por parte de las instituciones profesionales que definen la desviación como una conducta indeseable (Friedson, 1970). Rescato también el poder que ejercen ciertas profesiones, en particular la médica, como una forma de capitalizar control sobre su propio trabajo y establecer relaciones con el estado (Johnson, 1996).

En una línea similar resulta pertinente el planteo de Larson que desde una perspectiva histórica analiza los procesos cle creación de mercados y de obtención de legitimidad que encuentran concreción en un orden institucional y simbólico acompañados por la consolidación de cuerpos doctrinarios. Otras caracterizaciones sociológicas hacen hincapié en el carácter autorregulador de ciertas profesiones para adiestrar a nuevos miembros o admitirlos en la práctica para así implementar su especialidad según sus propios patrones, sin interferencias externas y respaldadas por el estado. La autorregulación, la adquisición de una destreza técnica que produzca resultados demostrables y la posibilidad de ser transmitida han sido históricamente considerados elementos centrales que definen a las llamadas profesiones "fuertes", como medicina y derecho (Collins, 1979).

A partir de la década del 1980 nuevas e importantes aproximaciones centran el análisis en las relaciones de los grupos profesionales con las élites políticas y económicas y con el estado, incorporando también el papel de las corporaciones en el mercado (Belmartino, 1988). Esto significa que el poder de jurisdicción sobre la definición y el manejo de los problemas sociales e individuales 
sobrepasa ampliamente los límites de los saberes y destrezas confiables que, en gran parte, sería el modo de operar de las instituciones profesionales en relación a las dimensiones políticas, gremiales, científicas y académicas que intervienen en la construcción de representaciones acerca del objeto de trabajo y en las formas de intervención. Construcción de carácter recursivo, ya que son estas representaciones las que a su vez orientan métodos, procedimientos de trabajo y normas con mayor - menor grado de proteccionismo para definir las relaciones con los colegas, con el objeto de trabajo y con otras jurisdicciones. Estas perspectivas estimulan la discusión de los procesos por los cuales las ocupaciones son profesionalizadas lo cual se vincula estrechamente al desarrollo del capitalismo en los siglos XIX y XX.

En consonancia, puede sostenerse que la principal definición de una profesión ha pasado históricamente por la obtención de una autonomía legitimada y organizada, es decir, por el control de su propio trabajo lo que significa el derecho exclusivo de determinar quiénes y cómo pueden ejercerla legítimamente.

La educación formal superior sería un requisito para la obtención de autonomía y autocontrol, pero el conocimiento en sí mismo no otorgaría ningún poder especial sino que éste puede alcanzarse cuando el conocimiento se torna exclusivo, habilitando para el ejercicio de una práctica, delimitando jurisdicciones profesionales garantizadas por el estado. Esta delimitación se establece como resultado de un conjunto de relaciones de carácter político que pueden mantener, mejorar o desplazar la posición de la profesión en el mercado. De este modo, queda en segundo plano el papel de la competencia esotérica especial, la calidad del trabajo y los beneficios para la sociedad.

Si bien históricamente, la creación de asociaciones profesionales fue clave para la definición de identidades corporativas y la reglamentación de las profesiones ha delimitado el "territorio profesional" asegurando el monopolio de competencia de la práctica, esta afirmación merece ser contextualizada. Basta como ejemplo el hecho que tanto en Europa como en Estados Unidos esas condiciones no fueron necesarias ni suficientes para la obtención de legitimidad y reconocimiento social de la profesión médica, excepto por la otorgación de un estatuto de legalidad. Tampoco establecieron el monopolio del médico sobre el trabajo de la cura ya que los médicos de la universidad y de las corporaciones formaron una élite menor hasta las primeras décadas del presente siglo.

La medicina constituye un ejemplo paradigmático de autonomía y control ya que está en condiciones de limitar la oferta de su propio trabajo y el de profesiones en cierto modo relacionadas. En el caso de la odontología, las definiciones ambiguas y conflictivas 
sobre la naturaleza del problema y de la práctica que interesa controlar (práctica ésta de escasa eficacia social alcanzada en tensión permanente con la medicina y con prácticas "irregulares", además de relaciones ambivalentes y contradictorias con el estado) han configurado, a lo largo del siglo XIX y primeras décadas del XX, un campo en disputa por la jurisdicción de un área particular. La jurisdicción y sus límites ha enlazado a la profesión odontológica con una problemática construcción de su identidad lo cual se vincula a la división social del trabajo en el campo de la salud, a los intereses de las asociaciones gremiales, a las representaciones de los odontólogos sobre sí mismos, a los desarrollos internos de las profesiones ligadas a la cura, al peso de diversos actores, a las nuevas tecnologías, a las formas de organización y a la existencia, creación y respuesta de los mercados.

\section{Eficacia social y ejercicio profesional}

Fueron las presiones de las primeras asociaciones gremiales, frente a la débil respuesta social alcanzada, las que impulsan el proceso de profesionalización de la práctica odontológica que se construye a partir de la disputa permanente por la exclusividad de un campo de intervención con las denominadas "prácticas irregulares".

A lo largo del siglo XIX y durante las primeras décadas del XX se intenta implementar un modelo asistencial incipiente integrado por médicos y religiosos y por ciertas estrategias de reglamentación y garantía. Sin embargo, su efectiva puesta en marcha fue lenta y difícil. Se puede señalar que aunque las expectativas y demandas de la población respecto a los servicios de salud probablemente eran bajas, las posibilidades científicas y técnicas también eran limitadas y prácticamente no existían grupos de presión alrededor de la atención médica. Así, el conflicto más importante se dirime en el espacio del curanderismo, práctica que carecía por sí misma de poder de negociación. Para los médicos esta competencia unificada contribuyó a definir - por oposición - su propio campo.

En esta época los conocimientos y la terapéutica no se diferenciaban demasiado unos de otros. El reconocimiento social era obtenido especialmente por aquellos "prácticos" de mayor experiencia, situación que se veía reforzada en ciertas circunstancias por el estado que particularmente en zonas del interior, en regiones poco pobladas y en áreas de frontera, aceptaba las prácticas denominadas "irregulares" por quienes también eran llamados "inteligentes" (Gonzalez Leandri, 1996).

La prohibición del ejercicio no era reconocida ni internalizada por vastos sectores de la población a lo que se agrega la escasez de médicos y odontólogos diplomados, quienes en lucha permanente 
por alcanzar la efectivización del ejercicio exclusivo, excluyen de la 'legalidad' tanto a barberos y sangradores como a dentistas extranjeros con reválidas sospechosas, a odontólogos con autorizaciones temporales e incluso, posteriormente, a los mecánicos de dentistas. El objeto de la disputa estaba constituído por un amplio mercado potencial que no podía recuperar para sí los beneficios de una supuesta eficacia terapéutica y que portaba un conjunto de representaciones y prácticas ligadas históricamente a las de los denominados "irregulares".

La determinación de atributos e incumbencias específicas de los odontólogos fue producto de una trama de relaciones conflictivas donde el clientelismo político y la centralidad del poder, expresado en el débil poder de ejecución otorgado a la conducción sanitaria (Departamento Nacional de Higiene1891 y Dirección de Salubridad Pública 1987), contribuyeron a que las demandas de reglamentación fueran permanentes. Por otro lado, el campo de intervención profesional se delimitó en el marco de una relación ambivalente, conflictiva y dependiente de la profesión médica ya reconocida socialmente $y$, a la vez, en una pugna permanente con los odontólogos empíricos (barberos, sangradores) que disputaban un mercado. La instancia que en principio otorgó reconocimiento formal a la práctica fue la universidad como institución estatal acreditadora de saber, lo que no guarda relación directa con la legitimidad social alcanzada en la época.

En consecuencia, quedaban pocos caminos para los herederos de los "prácticos de exodoncia" que no fuera la búsqueda experimental de alternativas para resolver los problemas centrales de salud bucal referidos al desdentamiento. Se plantea de este modo una estrecha vinculación inicial entre exodoncia y prótesis. Su desarrollo, hasta entrado el siglo XX, constituyó un buen indicador del estado del conocimiento, del peso de la definición inicial de una práctica y de la significación que pudo haber tenido la satisfacción de una demanda social que resultaba redituable en aspectos económicos y de prestigio social.

\section{Gremialismo odontológico: protegidos y expulsados}

Un reducido grupo de odontólogos auto convocados constituye la base de la creación de la Sociedad Odontológica del Río de La Plata en 1896, primera asociación gremial y científica, antecedente de la Asociación Odontológica Argentina (AOA). El objetivo es discutir una resolución del Departamento Nacional de Higiene respecto al control de enfermedades infecciosas que establecía disposiciones y normas ordenadoras del trabajo profesional, incluyendo también inspecciones periódicas a los consultorios particulares por parte de médicos de dicha instancia sanitaria. 
1 Del Estatuto de 1899 de la Sociedad Odontológica del Río de la Plata: "artículo 5: Sostener los derechos profesionales y proteger a sus miembros contra cualquier censura que a juicio cle la Asociación fuera injusta; 6: Combatir y perseguir el ejercicio ilegal de la profesión; $7^{\circ}$ : Gestionar ante las autoridades correspondientes la adopción de toda medida benéfica para la profesión; 80. Proteger a sus miembros pecuniariamente en caso de quedar imposibilitados para el ejercicio de la profesión."

2 Ver en Zarranz (1987): "Inglaterra fue el primer país que incorpora odontólogos como colaboradores de los cirujanos militares en la Guerra del Transwaal (18991902), pero fue recién en la Primera Guerra Mundial, cuando los países involucrados incorporan sistemáticamente odontólogos entre el personal militar sanitario."
Esta normativa provoca una fuerte reacción entre los odontólogos que rápidamente se congregan a fin de ofrecer un respaldo institucional a las negociaciones que se inician con niveles oficiales. De este modo, se sientan las bases de la organización gremial odontológica proponiendo, entre sus objetivos, además del impulso a actividades científicas, el sostenimiento de los derechos profesionales y la protección de sus miembros contra cualquier censura que a juicio de la asociación fuera injusta. Del mismo modo, se incluye el combate y la persecución del ejercicio ilegal además de la gestión ante autoridades públicas de medidas que beneficien a la profesión y signifiquen una protección pecuniaria (Sociedad Odontológica del Río de la Plata). ${ }^{1}$

Esta primera asociación, en el camino de su autonomía impulsado por quienes organizaron en 1892 el primer curso de odontología en la Facultad de Medicina de Buenos Aires, intenta promover el carácter científico de una práctica que hasta entonces era fundamentalmente empírica y limitada dando origen a un largo debate con la medicina. Este debate apuntaba con dificultad a la definición de un campo propio donde la práctica médica era considerada como un obstáculo ambiguo para el reconocimiento de la odontología por parte de la población. Así se creaban condiciones poco claras para el alcance de una jurisdicción propia. Algunos desencuentros con la medicina se producen en el terreno de una de sus especialidades: la radiología cuya incorporación a la atención "dental" en manos de médicos fue denunciada como "invasión al campo ajeno". Otra evidencia del conflicto se pone de relieve al promulgarse la Ley 2377 en 1899 con la creación de los Cuerpos de Sanidad del Ejército y la Armada. En esa oportunidad los odontólogos fueron, primeramente, excluídos de la posibilidad de pertenecer a dichos cuerpos. Cuando se los incorporó fueron relegados por largo tiempo a un segundo plano. Esto se siente como un agravio y un impedimento para alcanzar la jerarquización que representaba el ingreso a Sanidad Militar (Zarranz, 1987). ${ }^{2}$

En estas situaciones de disputa, toda la actuación de la Sección Seguridad Personal de la División de Investigaciones frente a los "ilegales", es bien recibida por la prensa odontológica. Al mismo tiempo se recogen expresiones de satisfacción ante la creación, en 1923, de la Inspección de Odontología (hasta entonces en manos de médicos) en el Consejo Consultivo del Departamento Nacional de Higiene. El eje de los reclamos, pugnando por obtener mayores posibilidades de poder, apuntaba a fortalecer la pertenencia, la identidad de intereses entre los legitimados y a participar en el propio control del ejercicio profesional. Las precisiones y reformas del Código Penal de 1922 restringen, no sólo el campo, sino las prácticas permitidas y obligan a las instituciones de policiales y de justicia a dar cumplimiento a las nuevas disposiciones. 
Tras cada avance obtenido en cuanto al reconocimiento y legitimación de la profesión, se abren nuevos flancos para los odontólogos dado que la profesión médica mantiene poderes de legitimación, exclusión y control de ciertas prácticas más allá de que éstas cuenten con la acreditación profesional correspondiente. Valga como ejemplo este irónico comentario: "los odontólogos que desean inscribirse en el Cuerpo Médico Escolar deben presentar un certificado de buena salud, una comprobación de su título y un testimonio de buena conducta ... todo ello certificado por un médico (La Tribuna Odontológica, 1923).

La creación en abril de 1924 de un comité ejecutivo ad-boc "pro-reglamentación de la odontología y represión del ejercicio ilegal" a iniciativa de un grupo gremialista más activo tiene por objeto desvincularse de las reglamentaciones dictadas para los flebótomos a fines del siglo XIX. Del mismo modo se pretende alcanzar la autorización para recetar medicamentos sin restricciones y sin depender de la firma autorizada de un médico. La antigua división, entre el exterior (barberos, peluqueros, sangradores etc.) y el interior del cuerpo (médicos) como límites definidores de territorios, continúa encontrando en la boca un punto de incertidumbre y entrecruzamientos de prácticas diversas.

En lo que se refiere a la defensa de intereses gremiales, los directivos de la AOA son vistos como débiles por los integrantes de la Subcomisión de Etica y Ejercicio Ilegal y por un grupo importante de asociados. Ello demuestra la heterogeneidad de esta institución que ha centralizado su acción en la difusión científica.

La propuesta de la subcomisión para combatir el ejercicio ilegal de la profesión, aceptada en 1929, intenta abrir la discusión sobre los lineamientos dentro de los cuales deberá desenvolverse la profesión y, a pesar de ser considerada insuficiente, apunta a lograr una reglamentación adecuada de la legislación existente. La intención es apoyar todo proyecto que reglamente el ejercicio de las profesiones médicas y centralice las actividades sanitarias (Higiene y Asistencia Médica Públicas) tratando de movilizar la participación del conjunto de los odontólogos dado que la acción gremial queda en manos de pequeños grupos.

Se propone la incorporación a la AOA de una Asesoría Legal que respalde y agilice las acciones policiales y jurídicas frente al ejercicio ilegal y se pone énfasis especial en recuperar y dotar de efectividad el cargo de Inspector de Odontología del Departamento Nacional de Higiene vigente desde 1923. Incluye, además, el establecimiento de relaciones permanentes con el Ministerio del Interior elevando un proyecto de ley y una solicitud de mayor cooperación policial. Para eso se propone la descentralización de los mecanismos represivos colocándolos en las seccionales policiales. 
En nombre de la ética, según algunos documentos analizados, toman preeminencia los fines sobre los medios al punto que la misma subcomisión explicita que "en general se trata de combatir a los falsos dentistas con sus mismas armas y utilizar todos los recursos, sean jurídicos o de orden de influencia personal para el logro de lo propuesto ... referente a las pruebas, aconseja el abogado éstas sean obtenidas por cualquier medio y que sean todo lo fehacientes que puedan ser..."

La defensa y protección de la profesión se hace escuchar también en asambleas científicas como lo expresa el dr. Canzani (1996b) en una conferencia de 1929 quien exalta las "perfecciones" de la Escuela de Odontología de Buenos Aires, coloca al odontólogo dentro de la élite profesional y social del país y ataca violentamente a quienes atentarían contra el perfil del profesional que imagina. Sus enunciados son duros y en su crítica incluye al poder político.

\begin{abstract}
Hay, señores, dentro de nuestra profesión un cáncer que la roe y que es imperdonable que lo hayamos dejado desarrollar a tal extremo: me refiero al ejercicio ilegal ... . Decir que el ejercicio ilegal de la profesión ha llegado ya a límites intolerables es repetir lo que todos los colegas conocen con minuciosa precisión; decir que ese ejercicio ilegal se efectúa a vista y paciencia de las autoridades, no es tampoco decir una novedad...
\end{abstract}

Coloca como modelo a imitar la legislación italiana de la época que reglamenta y limita las incumbencias del trabajo de los mecánicos y reprime el ejercicio ilegal con multas, confiscaciones de instrumental, clausura de locales y suspensiones.

La escasa respuesta obtenida hace suponer que la mayor preocupación de los odontólogos a nivel individual consistía en afianzarse económicamente a través de la profesión, delegando pasivamente en un pequeño grupo el compromiso de la actividad gremial. Ese reducido grupo de gremialistas está consciente del esfuerzo colectivo necesario para construir y afianzar todo el complejo sistema de ordenamiento de la profesión. En ese sentido, aunque se reconoce el espacio alcanzado en la universidad, se denuncia simultáneamente el desinterés y el individualismo reinante cuando se trata de asumir responsabilidades como cuerpo, ejerciendo presiones sobre el estado y reclamando un mayor espacio de poder en el campo sanitario. "Como no se trata de puestos que dan gloria y dinero, sino trabajo, no seremos nosotros los que elijamos sus miembros sino que esperamos que voluntariamente se ofrezcan a constituirlo..." (Revista Odontológica, 1929)

La preocupación central de la organización madre en las primeras décadas del siglo XX fue el mejoramiento de las "condiciones socio económicas del ejercicio profesional", la perse- 
cución del ejercicio ilegal y la vigilancia de toda legislación que pudiera afectar a la odontología (Canzani, op.cit.).

Desde la perspectiva de los odontólogos, la vigencia del "curanderismo" se explica en la capital del país por el relativo aislamiento de los barrios a los servicios públicos y a la clínica de la Escuela de Odontología. A la vez, se adjudica como una de las causas del "curanderismo" la propia debilidad y renuencia de los dentistas para defender sus derechos profesionales. Esa situación se atribuye también a una cuestión "cultural", ya que según la óptica de los odontólogos, la población privilegia el bajo costo a la "estética bucal", principio que parte del supuesto de la "incultura ciudadana". Este supuesto es reiteradamente esgrimido como factor explicativo que fundamentaría la necesidad de amparar a la población de los riesgos asociados a una elección equivocada de curadores.

La protección a la propia autonomía profesional es lo que define centralmente las relaciones de los odontólogos con el estado. Por un lado se apela al estado tratando de erradicar prácticas alternativas. Por otro, se presiona y se enfrenta al mismo cuando aparecen medidas desde instancias estatales (Departamento Nacional de Higiene) que intentan ejercer un control sobre las condiciones del ejercicio de la profesión (Belmartino, op. cit.).

Durante toda la década de 1920 y principios de 1930, tanto las asociaciones científicas y gremiales de la capital como las del interior del país, aún con diferencias internas, convergen en la tarea de obtener una legislación definitiva para el ejercicio de la odontología, lo que incluye el reclamo de aranceles máximos a los poderes públicos. Esta normatización, definida en 1932 (Santa Fe, Ley de Sanidad no 2287), trata de delimitar estrictamente el campo del ejercicio exclusivo de la profesión a partir de la posesión del diploma correspondiente expedido por universidades nacionales. Se habilita a los dentistas diplomados a dirigir establecimientos de asistencia odontológica públicos o privados, clínicas dentales escolares y servicio de odontología de los hospitales, siempre que estas instituciones estuvieran autorizadas por el Consejo Nacional de Higiene. Respecto al ejercicio ilegal establece penalidades específicas tales como clausura de locales, intervención en domicilios sospechosos y represión policial.

Simultáneamente, algunas medidas como la creación del Cuerpo Odontológico Escolar del Consejo Nacional de Educación y la Sección Odontológica del Departamento Nacional de Higiene van consolidando la presencia de la odontología en el campo de lá salud pública. La intensa convocatoria a los odontólogos, aún desde una entidad más elitista como el Círculo Odontológico, denuncia el predominio de los intereses económicos y de prestigio social de sus asociados: 
....recordemos aquello de que 'no sólo de pan vive el hombre'; no solamente en el consultorio debe hacerse la obra de nuestro engrandecimiento; hay que vivir no sólo con epicúreo; demos también vida al espíritu; somos combatidos y resistidos por la ignorancia del público en ciertas cosas, por los curanderos y por los malos colegas y si todavía dejamos algo a nuestra propia indiferencia y, digámoslo de una vez, a nuestro egoísmo estará todavía muy lejano el día en que el especialista de boca deje de ser considerado por legos y peritos como un vulgar sacamuelas (Revista Círculo Odontológico, 1930).

Se subraya aquí el accionar aislado e individual del profesional dedicado fundamentalmente al logro de su propio bienestar y se señala como importante la cuestión de la "cultura" del público, entendida como barrera a la cual hay que vencer. En esta lucha se incluye también a los "curanderos y malos colegas" que estrecharían el círculo de opositores.

\section{El intrusismo de los mecánicos}

Nacidos del mismo tronco artesanal que los odontólogos diplomados, los mecánicos de dentistas constituyen desde la primera década del siglo XX un numeroso grupo de practicantes que son sistemáticamente descalificados por los profesionales ya que significan una severa competencia. Se les adjudica fuertes falencias, desde la falta de asepsia hasta la incapacidad de tomar decisiones terapéuticas. Su accionar es denunciado hasta por servicios que realizan prestaciones gratuitas, como el "Instituto de Odontología de la Sociedad de Beneficencia de la Capital" (La Semana Médica, 1927).

En un proyecto de Ley de 1929, que reglamenta la profesión de dentista y su ejercicio en la provinvia de Córdoba, se establece que "los operarios a quienes el dentista confia la parte mecánica de su prótesis (mecánicos de dentistas) no podrán en ningún caso prestar asistencia ni ejecutar maniobra alguna en los pacientes" (artículo $7^{\mathrm{Q}}$ ). Enseguida se agrega que:

Se considerará como ejercicio ilegal de la odontología: a) al que careciendo de diploma de dentista o de doctor en odontología, original o revalidado en el país, se anuncie privada o públicamente con éste u otros títulos: mecánico dental, laboratorio dental, laboratorio de prótesis dental u otros títulos sinónimos o equivalentes o se anuncie de viva voz en las calles o plazas y utilice con el mismo fin intermediarios o recurra para ello al uso de placas, libretas, volantes, tarjetas o avisos en diarios o revistas de cualquier índole; b) a los mecánicos de dentistas a que se refiere el artículo séptimo ( $L a \mathrm{Voz}$ del Interior, 1929). 
Las asociaciones científicas también critican su práctica y la califican de "viciosa", sosteniendo que los mecánicos son "simples obreros manuales", encargados de trabajos materiales para prótesis y que deben realizar sus actividades bajo el control de un odontólogo. Se consideraba que no eran portadores del "arte de curar" sino de un "arte manual". Alrededor de 1930 se les prohíbe emplear la palabra 'dentista' en los anuncios públicos a fin de obturarles la captación de clientela.

En 1918, la reforma del estatuto universitario y especialmente la creación de las cátedras de técnica de prótesis y clínica protésica en la Escuela de Odontología de la Facultad de Medicina de Buenos Aires hacen que no prospere el proyecto de creación de una "escuela oficial" para los mecánicos. Unos años después la AOA intenta crear otra escuela bajo su dependencia, propuesta que fue rechazada por la Corporación de Protésicos Dentales interesados en que dicha escuela fuera creada dentro del ámbito universitario a fin de obtener mayor legitimidad. La AOA da cuenta de la existencia de cuatrocientos mecánicos agremiados y como modo de contener esta oferta y controlar los alcances de su formación sugiere que sea la facultad, a través de sus odontólogos, quien tome a su cargo el perfeccionamiento de sus conocimientos y que sea ésta la que reglamente y circunscriba sus funciones.

El mecánico es definido como un operario manual, un tallerista, un obrero, auxiliar del odontólogo que ejecuta su trabajo en el laboratorio sobre un modelo, siempre por indicación expresa del profesional. La prohibición de toda intervención ante el paciente queda plasmada en la reglamentación nacional de los "mecánicos para dentistas" en 1938.

A nuestro criterio el mecánico fue el precursor de las primeras prácticas odontológicas ligadas a la confección de prótesis y, como tal, depositario histórico del conocimiento empírico reconocido por parte de la población. A mediados del siglo XIX son los mecánicos quienes producen avances en la práctica técnica, acordes a los conocimientos de la época, contribuyendo a que la odontología se desprenda de la medicina.

Recién en 1937, el Consejo Superior Universitario aprueba la creación de un curso de "mecánicos para dentistas", semejante al de "auxiliaratos de enseñanza" de metalurgia, física, química y mecánica aplicada, pero tuvo corta duración.

\section{Nuevo modelo científico y campo profesional}

Con la creación de las escuelas y el impulso dado a la lucha contra el intrusismo, la práctica odontológica va construyendo con dificultad un campo propio donde, en alguna medida, la relación con la medicina operó como garantía de cientificidad. 
En este sentido los modelos científicos vigentes también contribuyeron a conformar un perfil que lentamente se va definiendo como "científico". La "teoría del foco" o "sepsis bucal" se abre paso a partir de 1920 y se avanza en la idea de la localización electiva de la infección en un órgano de menor resistencia, produciendo alteraciones patológicas. En esta concepción, se le atribuye a la infección dentaria una importancia fundamental en la génesis de infecciones generales como artritis, neuritis, miocarditis etc., aconsejando la eliminación precoz de los focos dentarios infecciosos. El modelo de la "infección focal" proporcionó una modalidad de intervención radical en odontología y en medicina, que tuvo expresiones paradigmáticas en la prescripción de extracciones dentales en masa concebidas como "preventivas", frente a la presencia de enfermedades desconocidas; y en la práctica de la extirpación rutinaria de amígdalas para obtener la 'cura' (Leonardo, 1983).

Según algunos autores, se inaugura así la odontología "moderna" que significaba la ampliación del campo de conocimientos, especialmente el de la patología clínica, a fin de profundizar el estudio de las enfermedades que, según dicho modelo, guardaban relación con el "sistema general del cuerpo". El conocimiento de la patología se plantea como indispensable para el reconocimiento científico de la profesión entre las demás ciencias

no necesitamos repetir que la patología se halla basada sobre los principios fundamentales de la medicina. Entonces iporqué los estudiantes de odontología no se matriculan junto con los estudiantes de medicina y prosiguen con ellos sus estudios durante los primeros años? ... yo no creo que el cirujano dentista debe ser primero médico antes de seguir vuestra especialidad, pero si estoy firmemente convencido de que junto con los estudios dentales los médicos deben ocupar un sitio importantísimo en nuestro plan de enseñanza (Fernández Dávila, 1918).

Se está pensando en que es necesario otorgar a la profesión una sólida base científica apuntando a equiparar el status del odontólogo con el del médico a partir de la profundización de conocimientos básicos comunes y de patología general. "Estamos haciendo demasiado mecánica dental, debemos asimilar más química, más histología, bacteriología, patología, hacer nuestros diagnósticos más precisos y correctos, haciendo de nuestra profesión una verdadera odontología preventiva" (idem, ibidem).

Se propone transformar el campo de intervención profesional de modo tal que se ligue a la prevención de "graves enfermedades del organismo humano" quedando en un segundo orden de importancia la prótesis e, inclusive, la "reparación de los dientes cariados". Ello 
tiene como objetivo la reformulación de una práctica que tome mayor distancia de acciones mecánicas y artesanales y que se sustente en fundamentos científicos. La incorporación de nuevas disciplinas en la formación universitaria y la aplicación de terapéuticas basadas en un conocimiento compartido con la medicina intervino en la construcción de una representación del cirujano dentista investida de mayor respeto, prestigio y consideración en el campo de las prácticas de la salud.

Dado que se consideraba que la teoría del foco había 'iluminado' a la odontología dentro de los llamados 'ramos menores' de la medicina, se plantea la necesidad de un mayor esfuerzo para alcanzar el reconocimiento pleno de una profesión que había tenido límites ambiguos. La concepción de la odontología como especialidad de la medicina fue una de las expresiones del carácter contradictorio y ambivalente de la relación establecida entre ambos campos, lo que queda ilustrado en numerosos testimonios de la época.

La evolución que ha tenido la odontología en los últimos lustros es tan considerable que hoy en día no es sino una de las especialidades de la medicina. La importancia de las relaciones de la cavidad bucal y la dentadura con el organismo es tan grande, y tan graves son los peligros que derivan de una boca en malas condiciones de higiene, que constituye un verdadero atentado a la Salud Pública. Así lo califica el Código Penal para el ejercicio de la odontología por personas no capacitadas para ello (Beltran, 1932).

Autores de la época consideran que con el advenimiento de la teoría de la infección focal ha perdido vigencia la concepción del cuerpo como conjunto de partes de la "máquina humana". Partes que se podían reparar, corregir, remover o reemplazar con ninguna o escasa relación con el resto del "organismo". El lugar decisivo que se le dió a los focos tóxicos orales, como responsables de procesos infecciosos a distancia, contribuyó a que el sistema "buco-dentario" ocupara un puesto sobresaliente en una explicación causal de la cadena "fisio-patológica" entendida linealmente. Esta concepción inaugura, en cierta medida, una representación de la práctica odontológica como 'científica', construída a partir de avances en la microbiología y bacteriología, que se afianza en la necesidad de garantizar una profesión y legitimarla socialmente, intentando producir así una ruptura con el conocimiento empírico.

En esta línea se entiende a la odontología como una especialización de la medicina, avanzando más allá del carácter manual y mecánico con que esta práctica había sido históricamente construída. Ser reconocidos por los médicos significaba para los odontólogos de la década del 1930, no sólo la integración en un 
paradigma científico que pivoteaba sobre el concepto de 'función' y de 'equilibrio orgánico', sino que representaba la posibilidad de consolidar la legitimidad formal, potenciar el reconocimiento social, conquistar un mercado y aumentar el prestigio social y económico.

\section{REFERENCIAS BIBLIOGRAFICAS}

Belmartino, S. et al. 1988

Beltran, J. 1932

Canzani, J. 1996

Collins, R. 1979

Fernández Dávila, $H$. 1918

Friedson, E. 1970

González Leandri, R. 1996

Johnson, $T$. 1996

La Semana Médica dic. 1927

La Tribuna Odontológica. jun. 1923

La Voz del Interior 31.8. 1929

Leonardo, M. et al. 1983

'Memoria del presidente del Circulo Odontológico' 1930

Revista Odontológica. jul. 1929

Zarranz, A. 1987
'Corporación médica y poder en salud. Argentina, 1920-45'.

Centro de Estudios Sanitarios y Sociales.

Organización Panamericana de la Salud (OPS), Rosario.

'Medicina legal para la enseñanza de la odontología legal y social'.

La Semana Médica. Buenos Aires, tomo 1.

'Asociación Odontológica Argentina, 100 años'.

Revista del Museo y Centro de Estudios Históricos de la Facultad de Odontología de Buenos Aires, año 11, $\mathrm{n}^{2} 21$.

The credential society: bistorical sociology of education and stratification. Academic Press, New York.

'Relaciones de la Odontología con la Medicina'.

La Tribuna Odontológica, año 2, $\mathrm{n}^{2}$, Buenos Aires.

Profession of medicine.

New York, Harper Row Publisher, Inc.

'Profesiones y procesos de profesionalización'.

Politica, médicos y enfermedades. Lecturas de bistoria de la salud en Argentina. Ed. Biblos/Universidad Nacional de Mar del Plata.

'Professions and power'. Em M. Lobato (comp.), Políticas, médicos y enfermedades. Lecturas de bistoria de la salud en Argentina. Ed. Biblos/Universidad Nacional de Mar del Plata.

Buenos Aires.

Año $7, n^{2} 6$.

Córdoba.

Endodoncia. Tratamiento de los conductos radiculares.

Buenos Aires, Ed. Panamericana.

Revista Circulo Odontológico,

año $2, n^{2} 5$.

No 7, tomo 17 .

'La función del odontólogo en el ejército: según la apreciación de un médico militar argentino en el año 1921'. Revista del Museo y Centro de Estudios Históricos de la Facultad de Odontología de Buenos Aires, año $2, \mathrm{n}^{2} 4$.

Recebido para publicação em novembro de 1997. 